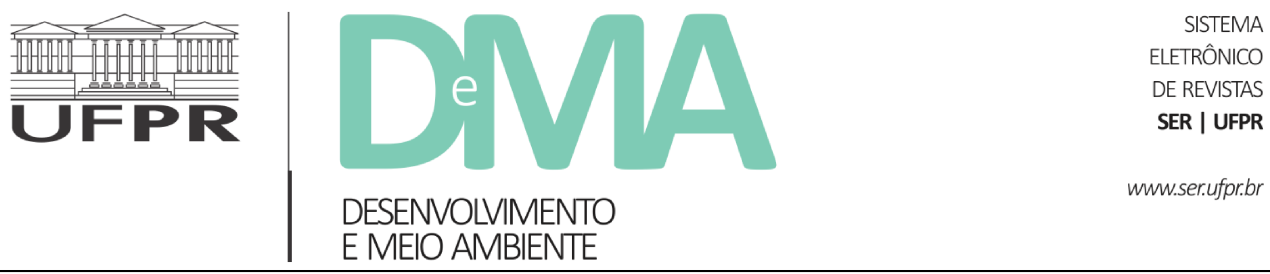

\title{
Governança ambiental e percepção sobre processos participativos na Reserva Extrativista de Canavieiras, Bahia, Brasil
}

\section{Environmental governance and perception about participatory processes in the Canavieiras Extractive Reserve, Bahia, Brazil}

\author{
Leriane Silva CARDOZO ${ }^{1 *}$, Daniela Trigueirinho ALARCON², Sofia CAMPIOLO ${ }^{3}$, Alexandre SCHIAVETTI $^{3}$ \\ ${ }^{1}$ Universidade Federal do Oeste da Bahia (UFOB), Barreiras, BA, Brasil. \\ ${ }^{2}$ Laboratório de Etnoconservação e Áreas Protegidas, Universidade Estadual de Santa Cruz (UESC), Ilhéus, BA, Brasil. \\ ${ }^{3}$ Universidade Estadual de Santa Cruz (UESC), Ilhéus, BA, Brasil.
}

*E-mail de contato: lerianecardozo@gmail.com

Artigo recebido em 9 de abril de 2018, versão final aceita em 1 de março de 2019.

RESUMO: Este estudo analisa os processos participativos no âmbito da Reserva Extrativista (Resex) de Canavieiras, unidade de conservação de uso sustentável situada na zona costeira do sul da Bahia e pertencente ao bioma marinho. A Resex de Canavieiras foi criada em 2006 e possui histórico de conflitos sociais desde o processo de sua criação. Neste estudo, identificamos os processos participativos por meio da análise dos princípios da boa governança - Legitimidade e Voz, Direção, Desempenho, Prestação de Contas e Justica - e a percepção dos beneficiários sobre o processo de criação e gestão da Resex utilizando pesquisa de natureza qualitativa, de caráter exploratório, com uso de técnicas de análise documental, observação não participante e entrevistas dirigidas aos membros do Conselho Deliberativo e pescadore(a)s da Resex. A análise dos dados se deu pelo método de Análise de Conteúdo para os dados de governança, e frequência de opinião dos entrevistados para análise de percepção. Verificou-se que os princípios da boa governança estão presentes nas descrições formais e nas ações desenvolvidas pelo Conselho Deliberativo da Resex de Canavieiras, com maior incidência para Legitimidade e Voz e a Direção. AAssociação Mãe dos Extrativistas da Reserva Extrativista de Canavieiras (Amex) influencia o processo de gestão da Unidade por meio da atuação dos conselheiros extrativistas. Com relação à percepção dos beneficiários, verificou-se que apenas $33 \%$ dos entrevistados afirmaram ter ouvido falar sobre Áreas Protegidas (AP), em contrapartida, 97\% dos entrevistados afirmaram saber da existência da Resex, embora somente 3\% compreendam seu significado. $\mathrm{O}$ estudo aponta que a área apresentava qualidade normativa característica de boa governança e que os 
beneficiários perceberam os benefícios trazidos durante o processo de implantação da área protegida.

Palavras-chave: conselho deliberativo; direção; legitimidade e voz; participação; pescadores.

ABSTRACT: This study analyzes the participatory processes in the context of the Canavieiras Extractive Reserve (Resex), a Sustainable Use conservation unit located in the coastal zone of southern Bahia and belonging to the marine biome. Resex de Canavieiras was created in 2006 and has a history of social conflicts since its creation. In this study we identified the participatory processes through the analysis of the principles of good governance - Legitimacy and Voice, Direction, Performance, Accountability and Fairness - and the perception of the beneficiaries about the process of creation and management of the Resex using qualitative research of an exploratory nature, using techniques of documentary analysis, non-participant observation and interviews directed to the members of the Deliberative Council and the fishermen of the Resex. Data analysis was conducted using the Content Analysis for governance data and frequency of respondents opinion for perception analysis. It was found that the principles of good governance are present in the formal descriptions and actions developed by the Deliberative Council of the Resex de Canavieiras, with greater emphasis on Legitimacy and Voice and Direction. The Mother Association of Extractivists of the Extractivist Reserve of Canavieiras (Amex) influences the management process of the Unit through the actions of the extractivist councilors. Regarding the perception of the beneficiaries, it was found that only $33 \%$ of the interviewees said they had heard about Protected Areas (AP); on the other hand, 97\% of the interviewees said they knew about the existence of Resex, although only $3 \%$ understood its meaning. The study points out that the area presented normative quality characteristic of good governance and that the beneficiaries perceived the benefits brought during the process of implementation of the protected area.

Keywords: deliberative council; fishermen; legitimacy and voice; management; participation.

\section{Introdução}

O bioma costeiro-marinho brasileiro possui, em 2018, 175 Unidades de Conservação (UC), sendo 72 UCs de Proteção Integral (41,1\%) e 103 UCs de Uso Sustentável (58,9\%) (MMA, 2019), das quais 31 são Reservas Extrativistas (Resex), sendo 28 federais e três estaduais (Prado \& Seixas, 2018).

As Resex visam a compatibilização da conservação da natureza com uso sustentável dos recursos naturais, sendo, portanto, relevantes espaços de interesses coletivos, valorização dos saberes tradicionais e desenvolvimento de processos participativos. Soma-se às Resex localizadas nas zonas costeira e marinha a necessidade de conservação do meio ambiente marinho e a adequada extração dos recursos pelas comunidades tradicionais, de forma sustentável (Vasconcellos et al., 2011).

A elaboração de uma estratégia de conservação baseada no uso tradicional desses recursos teve sua origem no movimento dos seringueiros ocorrido no Acre na década de 1970, uma ação coletiva contra os desmatamentos e expulsões das áreas florestais em defesa da produção extrativista e modo de vida, institucionalizada como política pública apenas em 1990 (Decreto $\mathrm{n}^{\circ}$ 98.897, de 30 de janeiro de 1990) no processo de regulamentação fundiária e ambiental (Allegretti, 2008). A autora destaca que os seringueiros assumiram a 
identidade coletiva de extrativistas, valorizando assim a sua atividade profissional, e as Resex surgiram como resposta às demandas de povos e comunidades tradicionais, resgatando dos movimentos indígenas o conceito de território e de áreas reservadas. No princípio de seu estabelecimento, as Resex não funcionavam como uma UC, mas foram definitivamente incorporadas ao Sistema Nacional de Unidades de Conservação (SNUC) por força de Lei Federal $\mathrm{n}^{\circ} 9.985$, de 18 de julho de 2000, regulamentado pelo Decreto $\mathrm{N}^{\circ} 4.340 \mathrm{de}$ 2002 (Brasil, 2002).

Esse modelo de UC foi utilizado pela primeira vez em sistemas costeiros em 1992, na região de Florianópolis - Santa Catarina, por extrativistas de berbigão (Anomalocardia brasiliana), dando origem a Resex de Pirajubaé (Allegretti et al., 2018). Posteriormente, as Resex marinhas foram replicadas ao longo da zona costeira brasileira com objetivo de minimizar os efeitos do desenvolvimento costeiro descontrolado e reforçar as reivindicações territoriais e de direito de uso dos recursos pelas comunidades tradicionais de pesca (Santos \& Schiavetti, 2013; Prado \& Seixas, 2018).

Quando as Resex são regulamentadas, o território passa a pertencer à União e é concedido para benefício da população tradicional por meio da Concessão de Direito Real de Uso (CDRU) (Brasil, 2002). As particularidades dos processos de gestão das Resex demandam o estabelecimento de procedimentos que garantam a participação qualificada da população local e o uso de metodologias que permitam a integração dos conhecimentos tradicionais com os técnico-científicos (ICMBio, 2009a). Além disso, segundo o Instituto Chico Mendes de Conservação da Biodiversidade (ICMBio), órgão executor das UC federais no país, com a criação das Resex, muitas mudanças ocorreram na forma como as populações tradicionais se organizaram e se apropriaram dos seus territórios. Tais mudanças, somadas às singularidades dessas UC, representam atuais desafios que exigem constantes adaptações e a elaboração de novas formas de governança e gestão ambiental.

De acordo com Santos \& Schiavetti (2014), em avaliação realizada sobre a gestão de 20 Resex marinhas por meio de indicadores ambientais, econômicos, institucionais e sociais, há uma tendência de melhora na efetividade de gestão das Resex, mas a maioria $(80 \%)$ dessas UC ainda possui gestão classificada como de baixa efetividade, sendo avaliada como padrão muito inferior a $40 \%$ ou inferior a $40 \%$ e maior que $55 \%$ de gestão. Os autores encontraram valores mais elevados para o âmbito ambiental, principalmente pela localização das Resex. Ou seja, elas foram criadas em áreas onde há a presença de espécies, as quais são utilizadas pelos proponentes. Esse fato vem corroborar a necessidade de se manter o sistema atual de solicitação de criação dessas áreas (bottom-up) e que a implantação das áreas foi realizada corretamente. Porém, no âmbito econômico, as áreas foram consideradas frágeis, pois há dependência quase exclusiva dos recursos naturais explorados, e caso haja alteração na produção ou mudança no valor do bem explorado acarretaria problemas sociais nas comunidades beneficiárias.

Definido pelo SNUC, as UC devem possuir conselhos consultivos ou deliberativos e ter representações dos órgãos públicos, sociedade civil e setor privado (Brasil, 2000). No caso das Resex, devem ser regidas por conselho deliberativo (CD) presidido por órgão executor ambiental da esfera de sua criação, composto por representação de 
órgãos públicos e da sociedade civil, visando a paridade (Brasil, 2002). No entanto a composição do conselho deverá ser majoritariamente formada por membros da população beneficiária (ICMBio, 2007). Em âmbito federal, compete ao ICMBio a presidência do $\mathrm{CD}$.

Conselhos representam regimes inovadores enquanto gestores de políticas públicas e devem dispor das capacidades necessárias para tornar suas ações também inovadoras (Jacobi, 2005). Cunha \& Loureiro (2009) destacam a relevência sobre a constituição do conselho, sendo esta muito mais importante do que a sua existência. Sendo instâncias deliberativas, com níveis de participação e pautados na democracia, os conselhos, por si só, dependerão da condução e dos interesses partilhados (Loureiro \& Cunha, 2008) para que garantam a participação efetiva dos atores sociais.

Estudos sobre conselhos gestores de Resex marinhas (Cardozo et al., 2012; Nobre \& Schiavetti, 2013; Nobre et al., 2017) apontam que eles têm funcionado para a implantação das UC, porém ainda com fragilidades em sua atuação.

Este estudo aborda os processos participativos no âmbito de uma UC federal de uso sustentável, categoria Resex, situada na área marinha e em faixa terrestre do sul do Estado da Bahia, denominada Resex de Canavieiras, constituída em 2006. Realizou-se esta pesquisa com o objetivo de identificar os processos participativos por meio da análise dos princípios da boa governança, descritos por Graham et al. (2003), e da percepção dos atores sociais - gestor, conselheiras e conselheiros, pescadoras e pescadores.

\subsection{Governança ambiental e processos participativos}

O termo governança não é novo, porém é complexo (Rhodes, 1996; Krahmann, 2003). Atribui-se ao cientista político Samuel Hunyington a primeira citação do conceito, na década de 1960 (Araújo, 2002). Distinto do conceito de governo - que se refere ao exercício do poder do Estado - e governabilidade, ao ato de governar a própria autoridade política ou legitimidade do Estado, a governança possui diferentes significados (Rhodes, 1996; Van Kersbergen \& Van Waarden, 2004) que são aplicáveis em diversos contextos.

Enquanto governo é caracterizado pela sua habilidade de tomar decisões e pela sua capacidade de aplicá-las (Abrams et al., 2003) a fim de manter a ordem pública e facilitar a ação coletiva, a governança atua como elemento norteador de políticas públicas (Câmara, 2013), compreendida, de modo geral, como a capacidade do governo de formular e implementar suas políticas (Araújo, 2002), por meio das estruturas e processos que permitam aos atores governamentais e não governamentais coordenarem suas necessidades interdependentes (Krahmann, 2003).

Araújo (2002) destaca que, assim como governabilidade, a governança não possui claramente uma definição, variando conforme autor, corrente ideológica e elementos. Presente nos debates acadêmicos e políticos mais recentes (Santos, 1997; Araújo, 2002), a governança decorreu das consequências de novas teorias modernistas e na reforma do setor público, a partir da década de 1980, que trouxeram à tona problemas de transparência e legitimidade, originando questões sobre a accountability ${ }^{1}$, tornando o desempenho mais relevante do que os procedimentos (Bevir, 2011).

\footnotetext{
${ }^{1}$ Não há consenso na literatura sobre o termo Accountability, que não pode ser traduzido diretamente para o português. O termo está cirscuncrito aos instrumentos de controle dos atos do poder público (Mota, 2007), requerendo transparência destes e capacidade de sançao dos gestores públicos pelos governados, que possuem instrumentos para monitorar o comportamento do poder público e responsabilizá-los por seus atos.
} 
No contexto brasileiro, reformas do Estado implantadas a partir de 1995 viabilizaram novos mecanismos de regulação e práticas dos serviços públicos aproximando-as do conceito de New Public Management (Filgueiras, 2018), cuja governança estava associada ao uso dos métodos utilizados pela sociedade para distribuir poder, gerir recursos públicos e problemas comuns (Gomides \& Silva, 2009). Contudo, crises econômicas e políticas, alinhadas à dificuldade da administração pública em adicionar valor aos serviços públicos, ampliaram o conceito de governança ao apresentá-la em forma de crítica à New Public Management, aumentando o escopo da atuação da gestão pública (além dos mecanismos e instrumentos de gestão) para as capacidades políticas da burocracia em atuar na direção de interesse coletivo (Filgueiras, 2018).

Em 2003, no V Congresso Mundial de Parques da União Internacional para a Conservação da Natureza (UICN) foi abordado pela primeira vez o tema governança em Áreas Protegidas (AP), sua relação com a conservação e equidade, a identificação dos princípios da boa governança e a avaliação da governança a partir do processo participativo (Borrini-Feyerabend, 2003). A UICN havia estabelecido como uma das principais estratégias de conservação da biodiversidade a criação de AP e a governança como o elemento central para efetividade e equidade no sistema de AP (Borrini-Feyerabend, 2004; Borrini-Feyerabend et al., 2017).

Na esteira dessa discussão, a Convenção para a Diversidade Biológica (CDB), na $7^{\text {a }}$ Conferência entre as Partes (COP), em 2004, recomendou aos países signatários integrarem a população local na gestão de AP no contexto socioeconômico local (Decisão VII/28) e por meio do Programa de Trabalho para Áreas Protegidas (PoWPA), que contemplava a governança, participação, equidade e distribuição de benefícios como objetivos para melhorar os benefícios sociais da AP. Essa decisão foi reconhecida como marco, indo além das iniciativas globais de conservação, por trazer a governança para o centro do planejamento e implementação, uma vez que as partes ao estabelecerem o PoWPA destacavam a má governança como um dos obstáculos ao alcance dos objetivos das AP. As COPs que se seguiram também abordaram a governança em AP, representando um avanço e reconhecimento, como a COP-10 que adotou o Plano Estratégico para Biodiversidade 2011-2020, também conhecido como Metas de Aichi (Borrini-Feyerabend et al., 2017).

A governança atua como uma forma justa e eficaz de governar (Abrams et al., 2003), exercendo de forma responsável os poderes (meios) a fim de atender aos objetivos (fins) da UC (Abrams et al., 2003; Graham et al., 2003) e está alicerçada na capacidade e na confiabilidade de instituições governamentais (regimes de governança) para responder eficazmente aos problemas por meio de acordos de consulta e negociação (Abrams et al., 2003). No âmbito dessas discussões, tem-se destacado o uso em acordos e convenções internacionais, em especial das Nações Unidas (Ivanova et al., 2007), por considerar que a governança influencia positiva ou negativamente a efetividade da gestão e determina a partilha de custos e benefícios relevantes (equidade da gestão). Newig \& Fritsch (2009) destacam a governança participativa, no contexto da análise multiníveis, para a melhoria da qualidade ambiental por meio da melhora da qualidade das decisões ao incorporar o conhecimento local aos processos de debates e à inclusão das partes interessadas, o que tende a facilitar a aceitação das decisões e a implementação. Eklund \& Cabeza (2017) esclarecem 
que há vínculo entre a qualidade da governança e efetividade para a conservação, porém tem sido geralmente negligenciada. Para os autores, a qualidade de governança está associada ao ambiente político no qual as instituições são organizadas, visando a eficácia do governo bem como a equidade e imparcialidade.

O termo boa governança surgiu na década de 1990 e foi descrito no documento do Banco Mundial sobre os problemas de desenvolvimento na África, entendido como uma crise de governança. Para essa instituição, boa governança era vista como sinônimo de uma gestão de desenvolvimento sólida (Leftwich, 1994). O termo foi sendo introduzido como dimensão normativa para avaliar a qualidade da governança (Santiso, 2001) que pode ser boa ou má, com base nos códigos da boa governança (Enrione et al., 2006) e a partir das boas práticas da governança, adequando-as à realidade do domínio público (Van Kersbergen \& Van Waarden, 2004) ao incorporar juízo de valor ou critérios normativos (Lee, 2003), bem como seus impactos, bons ou maus, porém nunca neutros (Simoncini et al., 2008). Quando é considerada boa, convencionou-se denominar boa governança (Sheng, 2010).

Boa governança e desenvolvimento sustentável são conceitos intimamente relacionados, contudo a boa governança não o garante, mas a sua ausência é capaz de limitá-lo e, na pior das hipóteses, de impedi-lo (Kardos, 2012). O atual desafio para as sociedades é fortalecer as instituições (regimes de governança), processos e mecanismos para que possam permitir a ampla participação da sociedade na definição de uma agenda para o desenvolvimento sustentável. Já os princípios da boa governança possuem relevância (Lockwood et al., 2010), pois servem para normalizar a governança e por especificar o que é desejável, ético e racional, fornecendo um meio para identificar e remediar práticas indesejáveis (Lockwood, 2010). Esses princípios podem ser percebidos como declarações normativas que indicam as qualidades que o regime deve possuir ou sugerem às autoridades responsáveis como devem exercer os seus poderes para atender aos seus objetivos (Davidson et al., 2006).

Sobre tais princípios, os estudos preparatórios desenvolvidos por Graham et al. (2003) e Abrams et al. (2003) para o V Congresso Mundial de Parques foram considerados decisivos para consolidar a temática governança (Borrini-Feyerabend, 2003). Graham et al. (2003) definiram cinco princípios da boa governança para AP, sendo legitimidade e voz, direção, desempenho, prestação de contas e equidade, com base nos critérios do Programa das Nações Unidas para o Desenvolvimento (PNUD), podendo estes serem aplicáveis a qualquer tipo de governança em AP, podendo haver sobreposição em face das influências sociais, culturais e históricas. Abrams et al. (2003) destacaram que os princípios propostos por Graham et al. (2003) poderiam contribuir para comparar as formas de governança e auxiliar na resolução de problemas e desafios, com a identificação de pontos fracos em regime de governança para fins de melhorias.

Diversos documentos e estudos endossam a relevância dos princípios de boa governança (Lee, 2003; Cozzolino, 2005; Arampatzis et al., 2006; Barett et al., 2006; Balloffet \& Martin, 2007; Dudley, 2008; Lockwood, 2009; Rauschmayer et al., 2009; Lockwood et al., 2010; Khan \& Bhagwat, 2010), incluindo, sobretudo, a necessidade de divulgação de boas práticas e disseminação de resultados (Arampatzis et al., 2006; Manos et al., 
2011). Na Tabela 1 são apresentados os princípios da boa governança e conceitos.

Grindle $(2004 ; 2007)$, de forma crítica, defende a existência da governança suficientemente boa, em oposição às mazelas da governança viciosa (Fonseca \& Bursztyn, 2009), por entender as influências do processo histórico e o foco nas relações de poder. Para a autora, a governança suficientemente boa permite que nem todos os déficits da governança precisam ser abordados de uma só vez, o que possibilita a existência de uma condição mínima para aceitação do desempenho do governo e sociedade civil, visto que cada país ou localidade apresenta limitações e oportunidades, e cujas estratégias de governança precisam considerar os contextos particulares e a análise de pontos fortes e fracos.

\section{Materiais e métodos}

Este estudo classifica-se como pesquisa qualitativa, exploratória, por meio de estudo de caso. O corpus da análise foi realizado com base em entrevistas realizadas durante o período de 2012 a 2014, observação dirigida e consulta a documentos oficiais. As pesquisas foram devidamente aprovadas pelo Sistema de Autorização e Informação em Biodiversida-de (Sisbio) concedida pelo MMA/ ICMBio, nº 25.121-1 e nº 35.991-1, e pelo Comitê

TABELA 1 - Definição dos princípios de boa governança, de acordo com alguns autores.

PRINCÍPIO

CONCEITO

\section{REFERÊNCIA}

Bernstein, 2005

Steffek, 2009
Legitimidade e Voz

Qualidade específica atribuída ao sistema de governança que gera conformidade com as normas, regras e decisões políticas, portanto, refere-se a instituições que trabalham em conjunto

Remete ao reconhecimento da existência de uma estrutura de poder que precisa ser legítimo.
Associado à visão estratégica. Requer alinhamento com as diretrizes internacional e nacional relevantes para a UC e guia de melhores práticas; Existência de legislação sobre objetivos para a UC; Definição de autoridade e responsabilidade aos envolvidos pela gestão da área. Instrumentos de governança; prevê organizações para gerir a UC contemplando a participação cidadã na tomada de decisões. Regras legalmente instituídas.
Graham et al., 2003

Graham et al.,

2003
Desempenho

Delimitação de metas e prazos para alcance de resultados. Compõe-se de eficácia e eficiência na consecução dos objetivos e na capacidade para realizar as funções necessárias ao mandato. 2003
Prestação de Contas

estina-se à gestão com comunidades locais, parceiros públicos e interessados envolvidos, processos de decisão. Envolve os cidadãos que concedem am plos poderes ao gestor para aplicar as políticas e leis e, em troca, exigem a prestação de contas.
Graham et al., Associado ao processo de tomada de decisão na gestão de UC, incluindo benefícios equitativos compartilhados entre os principais interessados. Estende-se além do domínio da lei, por contemplar tratamento de grupos que enfrentam práticas discriminatórias. Reconhecimento da importância das populações tradicionais no desenvolvimento e gestão de UC.
Graham et al., 2003 
de Ética da Pesquisa da Universidade Estadual de Santa Cruz, $n^{\circ} 312.404$ e protocolo 479/2011.

\subsection{Resex de Canavieiras: área de estudo}

A Resex Canavieiras situa-se em faixa terrestre e área litorânea localizada no sul do Estado da Bahia em territórios dos municípios de Belmonte, Canavieiras e Una e foi instituída em 2006 (Brasil, 2006). Possui área total de 100.726,36 hectares, sendo mais de $75 \%$ em ambiente marinho. Situa-se na poligonal da Zona de Amortecimento e Conectividade da Reserva da Biosfera da Mata Atlântica (RBMA) e no mini corredor prioritário Una-Lontras-Baixão do Corredor Central da Mata Attântica (CCMA). Dentre as principais atividades econômicas da região, destacam-se a pesca marinha e estuarina, agricultura familiar e pecuária. Registra-se que o município de Canavieiras ocupa posição de destaque como importante produtor no estado da Bahia para a espécie Caranguejo-Uçá (Ucides cordatus cordatus), um dos principais produtos da Resex (Aguiar et al., 2011; Souza, 2011).

No município de Canavieiras, com população de 21.798 habitantes (IBGE, 2010), reside a maioria dos beneficiários da Resex; os demais beneficiários residem em territórios dos municípios vizinhos: Belmonte e Una (32.336 e 24.110 habitantes, respectivamente), os quais possuem uma pequena parcela de seus territórios inseridos na área da Resex.

O Instituto Brasileiro do Meio Ambiente e dos Recursos Naturais Renováveis (Ibama) instituiu o Acordo de Pesca por meio da Instrução Normativa (IN) $n^{\circ} 83$, de 5 de janeiro de 2006 (Ibama, 2006), seis meses antes da criação da Resex, o qual estabeleceu normas para a gestão de uso sustentável de recursos pesqueiros no município de Canavieiras. As regras estabelecidas nesse acordo resultaram de reuniões realizadas com os pescadores do município. Foi estimado que $80 \%$ dos pescadores praticavam suas atividades nos manguezais e rios da Resex e o restante em área marinha, com atividades de pesca do camarão e peixes (Souza, 2011).

\subsection{Coleta e análise dos dados}

A coleta de dados deu-se por meio de análise documental, observação dirigida e entrevistas, tendo como público alvo os conselheiros do Conselho Deliberativo da Resex de Canavieiras (CDRC), titulares ou suplentes, e os pescadores beneficiários da Resex de Canavieiras. A observação dirigida teve como foco as reuniões do CDRC, do período de 2012 a 2014, e as atividades pesqueiras, sendo embarque e desembarque pesqueiro e beneficiamento e comercialização de pescado.

A avaliação sobre a percepção dos extrativistas em relação à Resex foi realizada mediante entrevistas (de abril de 2012 a agosto de 2013) com uso de roteiro semiestruturado. Como critério de seleção, considerou-se a atuação da prática pesqueira na área da Resex de Canavieiras, tendo a seleção dos pescadores e pescadoras com base na amostra não probabilística, de acordo com a disponibilidade do entrevistado e interesse em participar da pesquisa. Dentro do universo amostral possível, procurou-se abranger a diversidade de pesca praticada dentro da Resex, entrevistando-se extrativistas das diferentes localidades, idades e gêneros que atuam com todos os apetrechos de pesca registrados para a Resex e nos diferentes ecossistemas. Foram entrevistados tanto beneficiários que vivem exclusivamente da 
pesca como aqueles que complementavam suas rendas com recursos pesqueiros.

Sobre a análise da governança, foram utilizados documentos do CDRC (Regimento Interno, 21 atas de reuniões, atas de comissões e grupos de trabalhos, atos - ofícios e resoluções e dois planos de capacitação dos conselheiros) desde a sua criação em 12/11/2009 até 11/09/2014, seguido das entrevistas com os conselheiros (22 conselheiros do total de 25) ocorridas de dezembro de 2013 a agosto de 2014 com uso de um roteiro semiestruturado.

A análise dos dados foi realizada pelo método Análise de Conteúdo (Bardin, 2016) para os princípios de boa governança, e frequência de opinião para a percepção dos beneficiários da Resex de Canavieiras com relação aos processos participativos da UC.

\section{Resultados}

O Conselho Deliberativo da Resex de Canavieiras (CDRC) foi instituído por Portaria ICMBio $\mathrm{N}^{\circ}$ 71/2009 (ICMBio, 2009b) com a finalidade de contribuir para implantação da UC enquanto o seu Regimento Interno só foi aprovado em junho de 2012. Dentre suas atribuições, o CDRC deve aprovar desde o Plano de Manejo da Resex até projetos específicos de exploração sustentada de recursos naturais da Resex e instituição de grupo de apoio técnico/científico. Além dessa função, também deve representar a Resex de Canavieiras na estratégia dos Corredores Ecológicos da RBMA da Bahia.
Na ocasião da pesquisa, a Resex de Canavieiras não dispunha de Plano de Manejo e Plano de Gestão, tampouco havia sido assinada a CDRU pelo Governo Federal, visto que dependia do Perfil da família beneficiaria da Resex de Canavieiras. Tais conquistas deram-se aos poucos após a realização da pesquisa e cabe destacá-las aqui para melhor compreensão da área de estudo.

A CDRU foi assinada em 2015 e o perfil da família beneficiária da Resex de Canavieiras foi aprovado em 2016, conforme Portaria $N^{\circ} 79$, de 5 de agosto de 2016 (ICMBio, 2016). O cadastramento $^{2}$ das famílias beneficiárias teve início em 2014 e até 2018 mais de 1.700 famílias haviam sido homologadas. O Plano de Manejo da Resex encontra-se em fase de elaboração desde o início em 2018, com apoio do Projeto Áreas Marinhas e Costeiras Protegidas (GEF-Mar), projeto apoiado pelo Banco Mundial em parceira com o ICMBio que apoia a Resex desde 2015. Em 2018, teve seu Acordo de Gestão publicado - Portaria No 313 , de 12 de abril de 2018 (ICMBio, 2018).

\subsection{Princípios da boa governança}

Na ocasião da pesquisa, o CDRC compunha-se de vinte e cinco representações (Tabela 2) dentre órgãos federais, estaduais e municipais, instituição de ensino, associações, segmentos de artesãos e agricultores familiares, colônias de pescadores e organizações não governamentais.

Embora não estivesse registrada como membro do CDRC, a Associação Mãe dos Extrativistas

\footnotetext{
${ }^{2} \mathrm{O}$ cadastramento é um processo contínuo e o processo de homologação das famílias cadastradas até 2018 ainda não havia sido finalizado até fevereiro de 2019.
} 
TABELA 2 - Instituições públicas e da sociedade civil que compõem o Conselho Deliberativo da Resex Canavieiras.

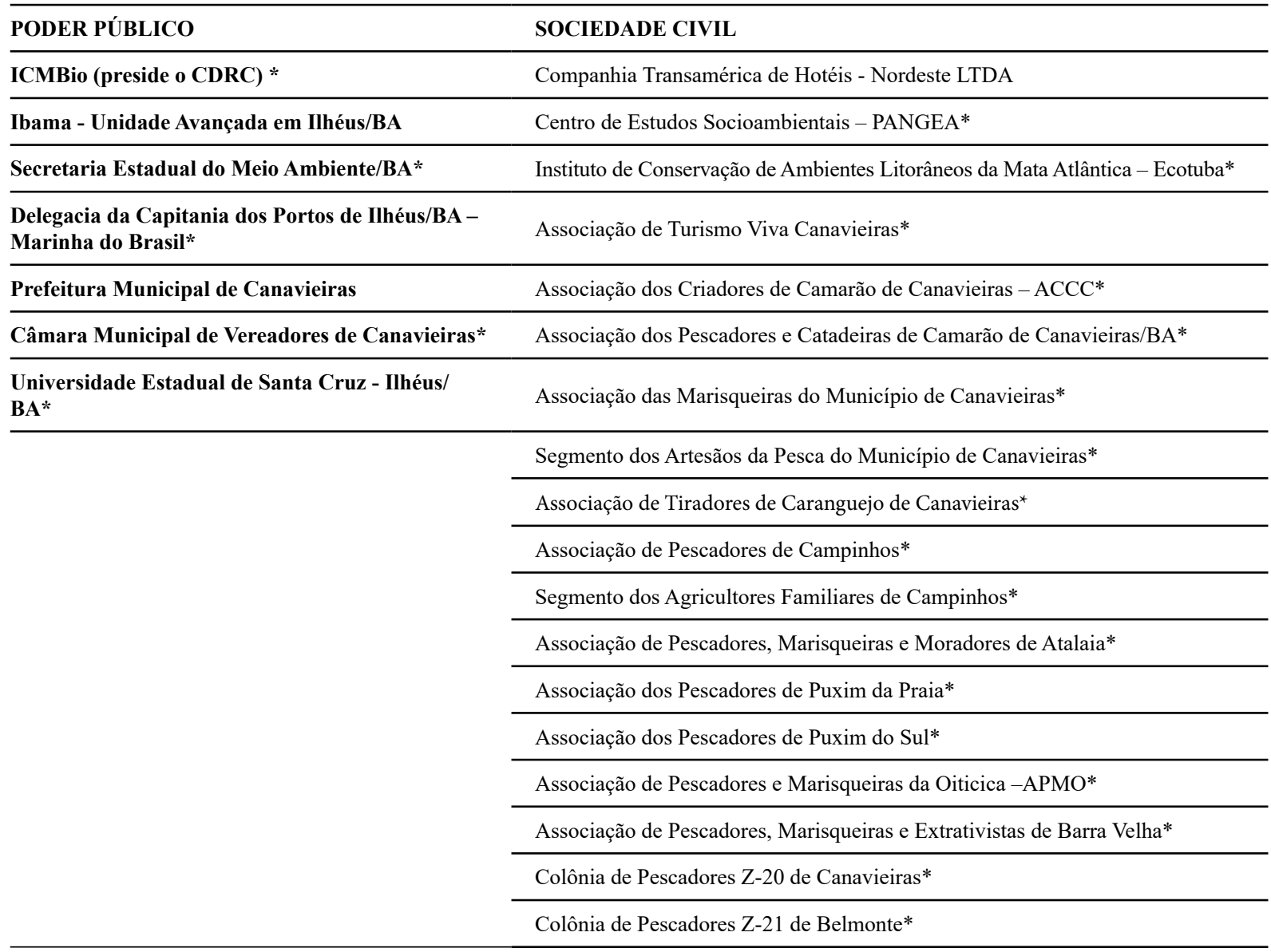

* Representantes do CDRC entrevistadas/os para esta pesquisa. FONTE: Dados da Pesquisa (2014).

da Resex de Canavieiras (Amex) exercia papel articulador e fundamental para a capacitação dos conselheiros e lideranças comunitárias, sendo, inclusive, percebida pelos conselheiros como a organização que mais contribui diretamente para esse fim, seguido do Pangea (com assento no CDRC), esta reconhecida como a organização parceira presente desde o levantamento de estudos para a criação da Resex. Há evidências da participação da Amex nos processos decisórios que antecedem as decisões do CDRC, por meio da atuação dos conselheiros extrativistas, que se organizam previamente para definição de prioridades e encaminhamentos. Como salientado pelo conselheiro entrevistado, os conselheiros estão qualificados para irem juntos em defesa dos seus objetivos, o que em entrevista 
concedida denominou de "Todos numa boca só" (Conselheiro A, Representante da Sociedade Civil, 2014) ao fazer alusão à coesão dos propósitos deste grupo. Essa característica também foi percebida posteriormente no estudo de Prost (2018). Destaca-se também a Amex na preparação dos conselheiros e lideranças comunitárias, bem como a preparação dos conselheiros para as pautas do CDRC, como registrado pelo conselheiro:

Nós temos hoje a Amex que está muito capacitada e é o braço direito da Resex. Esses parceiros nossos da Amex estão muito capacitados porque nós já estamos andando aqui desde 2001 juntos, são 13 anos de lutas, então essas pessoas aprenderam muito a dialogar, a discursar e a brigar, se for preciso (Conselheiro B, Representante da Sociedade Civil, 2014).

Também se verificou a contribuição de conselheiros e lideranças comunitárias em outras instâncias de participação social, por meio da atuação em demais conselhos e organismos de representação e de mobilização social, como a Comissão Nacional de Fortalecimento das Reservas Extrativistas Costeiras e Marinhas (Confrem), demonstrando haver troca de saberes e experiências que enriquecem o processo de empoderamento dos extrativistas. Constatou-se que os conselheiros fazem uso de consultas jurídicas para dirimir dúvidas técnicas e/ ou legais, tanto do ICMBio quanto de instituições parceiras (Pangea, Confrem). Tem-se como exemplo o Acordo de Pesca criado antes da UC que foi necessário remeter ao setor jurídico do ICMBio para averiguar a validade para replicá-lo no Plano de Manejo, conforme registro em Ata do dia 29 de setembro de 2011. A análise documental traz registros da presença de convidados em reuniões do CDRC de forma regular. Contudo não se verificou a participação destes em reuniões, salvo para apresentações de projetos específicos (a exemplo, quando solicitam pesquisa acadêmicas na UC)

\section{Princípio Legitimidade e Voz}

A data de posse dos conselheiros caracteriza a instalação do conselho, registrada em ata (IN ICMBio No 02 de 1997, Art.16, § $1^{\circ}$ ). Constatou-se o cumprimento da exigência jurídica de condução do CDRC por parte do órgão gestor, o ICMBio, e a existência de reuniões do CDRC com direito a voto, manifestação, com presença de convidados e da sociedade civil. Há constante participação do gestor e regularidade da participação da maioria dos conselheiros e lideranças comunitárias em reuniões do CDRC, porém baixa representatividade da sociedade civil (ONGs, moradores da Resex). Os planos de capacitação dos conselheiros são ou foram realizados após o processo de posse. Como instrumentos de gestão são utilizados: atas, atos, grupos de trabalhos e comissões, além das reuniões plenárias do CDRC. Verificou-se registro de poderes exercidos - poder de planejamento, regulação e celebração de acordos e financeiro. Nesse aspecto, $100 \%$ dos conselheiros entrevistados reconhecem que o CDRC exerce alguma forma de poder.

Constatou-se a gestão participativa, com envolvimento dos conselheiros nas discussões. Divergências são tratadas em reuniões, com direito a voto. Identificou-se participação do cidadão em níveis decisórios, com destaque especial para a Amex. Com relação ao conhecimento tradicional, os extrativistas contribuem e compartilham conhecimentos, que são levados em consideração nos processos decisórios. 
Em relação à partilha nas decisões com representantes locais (comunidade), não há mecanismos estabelecidos, embora a maioria dos entrevistados $(54,5 \%)$ afirmou que sempre há partilha das decisões com representantes locais. Documentos registram a presença de convidados e sociedade civil em reuniões do CDRC, de forma regular. Contudo constatou-se não ser uma constante o registro da presença deles nas atas. A fim de avaliar a participação nas reuniões, além dos conselheiros, foram verificadas as contribuições de convidados e sociedade civil aos debates e constatou-se que ocorreram a partir da apresentação de projetos e em contribuições aos temas discutidos, entretanto foi identificada baixa representatividade da sociedade civil nas reuniões do CDRC, salvo em relação a interesses específicos, e ausência de veículos de comunicação. Ressalta-se que a divulgação das reuniões acontece por meio do ICMBio e dos conselheiros. Em contrapartida, os entrevistados afirmaram (77,3\%) que a sociedade civil participa das reuniões quando convidada, o que reforça a necessidade de ampliar os espaços de veiculação e qualidade das informações do conselho.

\section{Princípio Direção}

Em relação a questão ambiental no âmbito do CDRC, através da análise documental, não se constatou referências explicitas às diretrizes internacionais e nacionais. Também não foram identificadas metas de médio e longo prazos. Porém verificou-se alinhamento do Acordo de Pesca (vigente) e do Plano de Gestão (em fase de elaboração) às estratégias do Plano Estratégico Nacional de Áreas Protegidas (Decreto $n^{0} 5.758 / 2006$ ), sendo importantes contribuições ao desenvolvimento da Resex. Em entrevistas, 45,5\% dos conselheiros afirmaram que a existência de um plano nacional contribui para acessar as políticas públicas. Verificou-se amplo conhecimento sobre a legislação federal que sustenta a Resex. Nesse item, cabe o destaque que $100 \%$ dos entrevistados afirmaram que o CDRC possui conhecimentos sobre o ordenamento jurídico que regula as atividades da Resex e, quando questionados sobre quais leis, $81,8 \%$ exemplificaram, sendo as principais: Acordo de Pesca, Defeso de Espécies, Lei de Crimes Ambientais e Sistema Nacional de Unidades de Conservação. A Resex de Canavieiras não possuía Plano de Manejo, o qual encontra-se em fase de elaboração, com participação do CDRC. Verificou-se pouca clareza sobre os planos de gestão, especificamente sobre objetivos e prazos. Contudo 59,1\% afirmaram que existe plano de gestão na UC, que seria correspondente ao Acordo de Pesca. Análise documental e entrevistas permitem afirmar o exercício da liderança por parte da gestão da UC, sendo que $86,4 \%$ percebem o gestor do ICMBio como participativo.

As características dos demais membros do Conselho, que exercem liderança, na opinião dos entrevistados, coadunam com as da gestão do ICMBio. Ressalta-se a explicação acerca da formação de lideranças como resultante de um processo histórico de luta e de mobilização social:

São lideranças que já têm uma carga histórica de luta, que não começaram necessariamente por participar do conselho, mas começaram lutando pela criação da Reserva Extrativista [...], houve uma visão de um espaço protegido [...] a partir da articulação com movimentos fora da Reserva Extrativista; que a formação não se dá necessariamente dentro de uma reunião de conselho, mas é um processo histórico e longo (Conselheiro C, Representante da Sociedade Civil, 2014). 
Destaca-se que a criação da Resex ampliou o acesso às políticas públicas, como, por exemplo, o Programa de Apoio à Conservação Ambiental - Bolsa Verde, parceria do Ministério do Meio Ambiente (MMA) com o Ministério do Desenvolvimento Agrário (MDA) e o Ministério do Desenvolvimento Social e Combate à Fome (MDS) e o Projeto Luz para Todos nas comunidades de Puxim da Praia e Barra Velha (Ata do CDRC em 25/3/2013).

\section{Princípio Desempenho}

As políticas ambientais aplicáveis à Resex de Canaveiras estruturam as condições para as etapas de: a) planejamento - reconhecimento da situação atual (diagnóstico socioambiental) e definição de metas e prazos -, e b) gerenciamento - conjunto de instrumentos utilizados para operacionalizar o planejamento por meio de mecanismos de comando e controle que, em alusão à teoria, podem ser preventivos e corretivos.

Com base em análise documental, não há evidência de plano de trabalho do CDRC de médio e longo prazos. Há registro de plano de trabalho da Amex como subsídio às ações do $\mathrm{CDRC}$, sendo inclusive lembrado por $81,8 \%$ dos entrevistados. Não foram identificados mecanismos de mensuração da avaliação de resultados e desempenho do CDRC (eficácia da gestão). Em entrevistas, 90,9\% dos conselheiros afirmaram que os resultados estão sendo alcançados.

Constatou-se que a gestão das Resex se concretiza pelas deliberações asseguradas pelo poder de voto e por meio dos Atos normativos do CDRC, competências definidas no Regimento Interno, como resolução, recomendação, moção e repre- sentação (Art.23ํ). Entretanto há evidências de preocupação sobre a normatização dos processos da Resex (Ata 13/9/13) para alcance de resultados. Normatizar implica definir regras, discuti-las e aprová-las em CDRC, dentro dos aparatos legais que as sustentam. Tem-se como exemplo o Perfil do Beneficiários da Resex, definido por meio de resolução, que viabilizou o acesso às políticas públicas.

Acerca das condições necessárias ao exercício do papel do conselheiro, constatou-se que há capacidade de executar as tarefas, aspecto endossado pelas entrevistas (90,9\% concordam). Em relação à capacidade de coordenar atividades com representantes do governo e da sociedade civil, não foi identificado nenhum registro em desacordo, sendo ratificado pelos entrevistados (77,3\% concordam). Não há registro documental de prestação de contas ao público, embora $45,5 \%$ dos conselheiros afirmassem que há prestação de contas (o que entendem ocorrer no momento das reuniões).

Contudo ressalta-se que o CDRC busca atender as demandas e problemas da comunidade e, como recurso, utiliza-se da criação de comissões (Comissão de Análise e Emissão de parecer referente ao projeto de perfuração petrolífera da empresa Queiroz Galvão na área BMJ2, em 09/2/10; Comissão Técnica para acompanhar pesquisas realizadas na Resex e entorno, em 10/11/10; Comissão de Análise e Emissão de parecer referente à Autorização Direta do CDRC, em 16/7/12; Comissão de Proteção do CDRC, em caráter permanente, 12/9/12) e grupos de trabalho (GT sobre turismo desordenado, em 10/11/10; capacitações dos conselheiros, em 28/6/12; perfuração marítima do Bloco BM-J-1 da Petrobras na Bacia do Jequitinhonha, em 28/6/12; elaboração do Acordo de Gestão, em 12/9/12; análise dos dados do cadastramento de beneficiários 
existentes, em 12/9/12; Proteção do norte centro e sul - Hotel Transamérica, em 11/12/12; Barragem de Itapebi para elaboração de carta denúncia, em 11/12/12; Elaboração de proposta de parecer ao processo de Licenciamento da perfuração do Bloco BMCAL-11 e 12 Bacia Camamu-Almada, em 06/3/14).

Acerca dos aspectos formais de condução do conselho, os documentos analisados comprovam a regularidade dos registros e cumprimentos das exigências estabelecidas pela IN ICMBio 02/1997, como convocatórias, registros, posse, reuniões, encaminhamentos e ofícios.

\section{Princípio Prestação de Contas}

Por meio de análise documental, pode-se afirmar que as responsabilidades do CDRC estão descritas em Regimento Interno, devidamente aprovado. Tal documento foi amplamente discutido e avaliado pelos pares na fase de sua elaboração. Em relação à responsabilização no que compete à autoridade para agir, verificou-se a existência das deliberações do conselho, sendo confirmadas por entrevista com 86,4\% dos conselheiros.

Sobre a prestação de contas, de acordo com SNUC, as competências do Conselho limitam-se à avaliação do orçamento da Unidade e relatório financeiro anual. A IN ICMBio No 02/2007, ao disciplinar as diretrizes, normas e procedimentos para formação e funcionamento do conselho, não especifica o ato da prestação de contas do conselho como uma de suas competências, porém declara que cabe promover ampla discussão sobre o papel da Unidade e sua gestão. O Regimento Interno do CDRC, ao posicionar-se sobre o assunto, não faz referência à prestação de contas ao público e, ao se referir à gestão da Unidade, estabelece periodicidade anual. Não há registros formais (rotinas e procedimentos) para prestação de contas das ações do CDRC, embora 59,1\% dos entrevistados tenham afirmado que o CDRC a realiza. Acerca de qual instituição se destina a prestação de contas, verificou-se que ocorre do órgão gestor em nível local à instância federal, como prestação de contas institucional.

Em relação a disponibilização de informações e meios de comunicação, ocorrem apenas por consultas presenciais à sede do ICMBio e da Amex. Não há referência a outros recursos de acesso à informação. Nesse aspecto, 86,4\% dos entrevistados relataram que as informações estão acessíveis e que são divulgadas, mas que ficam restritas ao conselheiro. Registra-se a disponibilidade das informações in loco, o que endossa a entrevista, visto que $86,4 \%$ dos conselheiros afirmaram haver transparência no acesso às informações.

\section{Princípio Equidade}

Documentos comprovam a existência de apoio jurídico, com envolvimento de outras instituições de apoio, a exemplo do Ministério Público Federal. Ao serem questionados, todos os entrevistados reconheceram a existência de apoio jurídico, que fazem uso sempre que julgam pertinente e não registraram nenhum obstáculo ao seu direito assegurado. Em relação à aplicação equitativa, imparcial e efetiva das regras, verificou-se ampla discussão no conselho e aceitação dos critérios definidos pelo grupo. Em documentos, não há registros de atos que desabonem esse critério. Contudo, embora se reconheça a necessidade de existência de regras que conduzem 
as ações do conselho, $27,3 \%$ dos entrevistados não souberam informar qual documento descreve as regras, o que não diminui em importância, mas ressalta a necessidade de orientações.

Acerca de usos e saberes das comunidades tradicionais, há registros de respeito aos conhecimentos tradicionais, inclusive que auxiliam as ações e deliberações do CDRC. Em entrevista, $90,9 \%$ dos conselheiros afirmaram que existe o respeito às práticas das comunidades tradicionais e, quando questionados se tais usos e saberes contribuem nas decisões do CDRC, todos afirmaram que são incorporados às atividades, $o$ que corrobora com os registros em documentos.

\subsection{Percepção das pescadoras e dos pescadores}

Foram entrevistados 98 pescadores, 68 homens e 30 mulheres. Do total de entrevistados, a maioria (44\%) declarou ter optado pela pesca como atividade por falta de opção, $23 \%$ porque gosta ou dentre as atividades que sabe exercer é a que prefere, $7 \%$ por necessidade, e com menores porcentagens variando entre 4 e $6 \%$, foram citadas como motivações: tradição familiar, liberdade da profissão, retorno financeiro rápido e profissão que no passado dava dinheiro. A combinação de mais de um fator também foi citada por 3\% dos entrevistados, sendo que nesses casos, a falta de opção profissional sempre esteve incluída nas respostas.

Quando questionados sobre o que é uma UC, apenas $33 \%$ do grupo entrevistado afirmou já ter ouvido falar, por meio televisivo ou pela atuação local do ICMBio e mediante palestras ministra- das na Colônia de Pescas Z-20 Canavieiras. No entanto $89 \%$ não souberam responder o que seria uma UC, $10 \%$ sabiam alguns elementos do que seria uma UC e apenas $1 \%$ soube afirmar com precisão de que tratam as UCs.

Em relação à Resex de Canavieiras, 97\% do grupo de pescadoras e pescadores afirmaram saber da sua existência, sendo que $91 \%$ sabem que realiza suas práticas pesqueiras em uma Resex. No entanto somente $3 \%$ souberam afirmar com precisão o que é uma Resex, e 43\% souberam elencar alguns elementos dessa categoria de UC.

Embora tenha sido demandada pelos pescadores, o processo de criação da Resex de Canavieiras foi bastante conflituoso em função dos interesses dos empresários que atuam na região no setor imobiliário e na carcinicultura. Ao longo das entrevistas, verificou-se que esses conflitos dificultam a aceitação da Resex por parte de alguns representantes da classe pesqueira, o que, infere-se, pode afetar a gestão desta UC. Além disso, registra-se relatos sobre a pouca atenção recebida do governo federal e a morosidade dos processos de criação dos instrumentos de gestão, que interferem no nível de confiança no órgão gestor e no $\mathrm{CD}$, reduzindo o grau de participação das pescadoras e dos pescadores na gestão da UC.

Do grupo de pescadoras e pescadores entrevistados, somente $28 \%$ afirmaram ter participado, de alguma forma, do processo de criação da Resex de Canavieiras, tendo a participação nas reuniões sido flutuante.

Em relação à opinião dos participantes em relação à UC, houve aumento do número de pescadoras e pescadores favoráveis à Resex ao longo do tempo. Vale destacar que um pequeno percentual de entrevistados (5\%) afirmou que 
TABELA 3 - Opinião de pescadoras e pescadores da Reserva Extrativista de Canavieiras entrevistados entre 2012 e 2013 sobre a criação e a situação atual da Unidade de Conservação (UC).

\begin{tabular}{lll}
\hline Tipo de Opinião & Sobre a Criação da UC & Sobre a UC no momento da entrevista \\
\hline Favorável & $23 \%$ & $39 \%$ \\
\hline Contrário & $32 \%$ & $30 \%$ \\
\hline Desconhece & $5 \%$ & $5 \%$ \\
\hline Sem opinião formada & $40 \%$ & $26 \%$ \\
\hline & $100 \%$ & $100 \%$ \\
\hline
\end{tabular}

continuava a desconhecer a existência da UC mesmo seis anos após sua criação (Tabela 3).

Após decorridos seis anos da criação da Resex, apesar dos entrevistados terem reconhecido diversos benefícios trazidos pela implantação da Resex para os trabalhadores da classe pesqueira (ex.: fortalecimento das associações, construção e reforma de casas populares, financiamento de artefatos de pesca, doação de kits para marisqueiras e Bolsa Verde), esses benefícios ainda eram recentes e, portanto, muitas vezes apontados como deficientes ou como insuficientes para justificar a criação da área.

As pescadoras e os pescadores entrevistados que se declararam na época contrários à Resex, destacaram o impedimento da instalação de empreendimento turístico de grande porte, com potencial de absorção de mão de obra local, proibições vinculadas à criação da Resex (como a venda de imóveis) e a presença constante de órgãos fiscalizadores. No entanto, como ressaltado por um dos entrevistados, muitas dessas proibições não são provenientes da criação da Resex, mas sim da legislação pré-existente, pois o território atual da Resex possui uma parcela em área terrestre que já era pertencente à União. Nessa área, as indenizações a serem realizadas, quando couber, serão somente pelas benfeitorias existentes.

\section{Discussão}

Foi identificada uma governança pautada na multiplicidade de atores, com forte atuação da representação das populações tradicionais, cujas bases comunitárias são consultadas para subsidiar processos decisórios. Direitos legítimos, como liberdade de expressão e equidade a todos os atores são formalmente assegurados. Constatou-se que as comunidades da Resex participam das reuniões do conselho, embora de forma tímida. Em relação às representações previstas no $\mathrm{CDRC}$, verificou-se que há participação, contudo considera-se preocupante a ausência do poder público municipal nas reuniões, especificamente a Prefeitura do Município de Canavieiras. Em face da ausência, em 2015 houve exclusão do poder público municipal do assento do CDRC (Dias et al., 2018).

Verificou-se existência de poder para exercer a função do Conselho e capacidade de executar suas 
atribuições. No contexto da Resex, o ordenamento jurídico por meio da IN ICMBio No 02 de 2007 assegura poderes, explicitados através da garantia aos direitos e à participação das populações tradicionais na gestão da Unidade (Art.15) e, especificamente sobre as competências do Conselho Deliberativo (Art.17), dentre outras, de deliberar acerca de processo decisorial. Como legitimidade do poder conferido aos extrativistas, a composição do conselho assegura a maioria de representantes das populações tradicionais (IN ICMBio $\mathrm{N}^{\circ}$ 02/2007, Art.9 ${ }^{\circ}$, parágrafo III), o que se traduz pelo Regimento Interno em condições de voto, sendo no mínimo $51 \%$ dos votos dos conselheiros reservados aos extrativistas representantes das comunidades tradicionais inseridas na Resex $\left(\operatorname{Art} .2^{\circ}\right)$. Nessa configuração está implícita a importância da participação dos extrativistas no processo de gestão da unidade, com destaque para o poder atribuído a eles. Essa questão é compreendida pelos extrativistas a partir de alinhamento prévio à reunião do $\mathrm{CDRC}$ a fim de assegurar as decisões.

Com base na literatura e a partir da análise de documentos e entrevistas, depreende-se que há exercício dos poderes de planejamento e execução (Graham et al., 2003) pelo CDRC e há percepção sobre isso por parte dos membros do conselho, pois todos os conselheiros entrevistados afirmam que o conselho exerce poder, enfatizado pelos instrumentos de gestão exercidos, tais como Grupos de Trabalhos e Comissões.

Em relação à Direção, resultados alertam para necessidade de melhorias, em especial relacionadas ao Plano de Gestão da Resex, com definição de objetivos, planos de trabalho, indicadores e metas de médio e longo prazos. No entanto, verificou-se que há participação dos conselheiros na elaboração de planos específicos, o que comprova o envolvimento deles na gestão, como destacado em entrevistas. Nesse aspecto, sobressai o planejamento da Amex, que contribui para direcionar os debates no CDRC, por meio de reuniões prévias de planejamento e ação, instruindo-os sobre as pautas de debate. Em especial, registra-se a falta de recursos para gerir a unidade, reiteradamente destacado em documentos e entrevistas, o que endossa a necessidade de um planejamento federal para criar e gerir as UC, na mesma forma e intensidade que se cobra a gestão das AP. Ressalta-se a necessidade de captação de recursos para apoio a projetos, a partir de órgãos financiadores e organizações nacionais e internacionais, a fim de viabilizar a existência e continuidade de ações. Destaca-se a atuação das lideranças comunitárias, principalmente se avaliadas as dimensões geográficas da Resex de Canavieiras e as diferentes comunidades existentes.

O Desempenho, diretamente relacionado à prática da gestão, aponta para as dificuldades de acompanhamento e controle das ações da Resex, o que endossa a necessidade de melhorias na Direção. Outra consideração envolve a prestação de contas ao público e registros de críticas e reclamações públicas. Esses itens demonstraram que há pouca interação com a sociedade civil (população local, beneficária ou não da Resex), no sentido de expor as informações, bem como registrar suas críticas, o que pode ser inferido do fato de que os conflitos no processo de criação da Resex persistem até dias atuais.

Como ponto forte, destaca-se a preocupação do gestor, conselheiros e comunidades com riscos (danos ambientais), embora não se possa afirmar que existe a gestão de riscos propriamente dita, pois ocorre de forma empírica, tímida e sem método descrito, além da ausência dos recursos necessários; no entanto o que é realizado contribui para minorar os 
riscos ambientais e, principalmente, torna-os envolvidos na gestão vigilante da área que representam.

A Prestação de Contas apresenta mais fragilidades e carece de maior atenção por parte do CDRC. Requer que sejam definidos mecanismos para assegurar que processos de prestação de contas e responsabilização sejam praticados de modo rotineiro e normatizado. Essa fragilidade decorre, em grande parte, dos princípios anteriores - Direção e Desempenho -, que à medida que apresentam pontos fracos em planejamento e execução, certamente apresentarão nesse princípio. Essa fragilidade citada pode ser percebida pela percepção dos conselheiros, pois apenas $31,8 \%$ dos entrevistados consideraram que a prestação de contas se destina a todos. Como explicitam Graham et al. (2003), Prestação de Contas envolve controle e avaliação das ações, de forma vertical e horizontal. Não se verificou prestação de contas em nenhum dos dois sentidos.

A Equidade, vinculado ao processo de tomada de decisão com inclusão de benefícios equitativos compartilhados, atende às necessidades, visto que há desempenho que comprova sua existência, tais como respeito e uso dos conhecimentos tradicionais, deslocamento do poder central para as bases comunitárias, aplicação de regras, que no caso foram discutidas e acordadas pelas partes interessadas, e equidade na aplicação das regras. Destaca-se que, em entrevistas, a maioria absoluta dos conselheiros $(90,9 \%)$ afirmou que houve melhoria na equidade com a criação da Resex.

Pode se afirmar que os mecanismos estabelecidos pelo CDRC asseguram as condições para que os conhecimentos tradicionais sejam considerados nos processos de gestão, o que atende o objetivo explícito da Resex. A Resex de Canavieiras apresenta ainda características de Governança Participativa, corroborando com Newig \& Fritsch (2009), por incorporar o conhecimento local aos processos de debate e tomada de decisões.

\section{Considerações finais}

Em relação aos princípios da boa governança, conclui-se que a Resex Canavieiras apresenta qualidade normativa característica de boa governança com critérios a serem desenvolvidos e melhorados, principalmente em relação à Direção e Desempenho.

A análise em nível de princípio permite concluir que todos estão contemplados, o que é comum se considerados aspectos históricos e culturais. Reconhece-se como relevante a importância das instituições formais, em especial a Amex, por contribuir como agregadora dos extrativistas e desenvolver lideranças locais, permitindo a continuidade das ações e a mobilização social em favor de maior participação da sociedade. Entretanto, como limitações, destaca-se o não envolvimento do poder público municipal, em face de sua ausência nos processos deliberativos da CDRC.

Recomenda-se a realização de trabalhos futuros, em continuidade ao presente, a fim de verificar como os princípios da boa governança estão sendo fortalecidos e como podem auxiliar na efetividade da gestão e melhora da qualidade da governança, bem como estudos que contemplem princípios de governança associados a regimes da governança e à dinâmica de escalas.

Em relação à percepção das pescadoras e dos pescadores, é possível avaliar que houve maior aceitação da Resex ao longo do tempo, com aumento de sua aprovação e redução do número de representantes do setor pesqueiro contrários à UC ou sem opinião formada. 


\section{Agradecimentos}

Os autores agradecem aos membros do CDRC e aos beneficiários entrevistados pela disponibilidade e oportunidade. À Fundação de Amparo à Pesquisa do Estado da Bahia (Fapesb) e ao Conselho Nacional de Desenvolvimento Científico e Tecnológico (CNPq) pelo apoio financeiro, à Coordenação de Aperfeiçoamento de Pessoal de Nível Superior (Capes) pelas bolsas de doutorado das duas primeiras autoras e ao $\mathrm{CNPq}$ pela bolsa de produtividade do último autor. Ao projeto Capes Ciências do Mar I "Formação de Recursos Humanos para a Concepção, Consolidação, Gestão de Políticas Públicas de Conservação e Manejo de Recursos Naturais Renováveis e Áreas Marinhas Protegidas", Parceria Universidade Federal Fluminense - Centro Nacional Patagônico - Universidade Estadual de Santa Cruz, e à Universidade Estadual de Santa Cruz pelo apoio logístico e financeiro para os eventos de integração entre os parceiros e as discussões sobre a temática Resex.

\section{Referências}

Abrams, P.; Borrini-Feyerabend, G.; Gardner, J.; Heylings, P. Evaluating Governance. A Handbook to Accompany a Participatory Process for a Protected Area. Manuscript, Parks Canada and TILCEPA; Governance of Protected Areas, 2003. Disponível em: https://portals.iucn.org/library/ node $/ 12430$

Aguiar, P. C. B.; Moreau, A. M. S. S.; Fontes, E. O. Impactos na Dinâmica Ambiental do município de Canavieiras (BA) tendo a RESEX como fator de influência. Revista GEOMAE - Geografia, Meio Ambiente e Ensino, 2, 61-78, 2011. Disponível em: http://www.fecilcam.br/revista/index. php/geomae/article/view/27

Allegretti, M. A construção social de políticas públicas.
Chico Mendes e o movimento dos seringueiros. Desenvolvimento e Meio Ambiente, 18, 39-59, 2008. doi: 10.5380/ dma.v18i0.13423

Allegretti, M.; Cunha, L. H. O.; Schmink, M. 30 anos do Legado de Chico Mendes. Desenvolvimento e Meio Ambiente, 48, 1-6, 2018. doi: 10.5380/dma.v48i0.63011

Arampatzis, S.; Manos, B.; Manou, D. Governance and Ecosystems Management for the Conservation of Biodiversity. In.: Proceedings of the 4th Internacional Conference on Citizens and Governance for Sustainablem Development (CIGSUD), Vilnius Lithuania, September. 2006.

Araújo, S. Conceituação de governabilidade e governança, da sua relação entre si e com o conjunto da reforma do Estado e do seu aparelho. Textos para discussão e Ensaios: [45]. ENAP, 2002. Disponível em: http://repositorio.enap. gov.br/handle/1/661

Balloffet, N. M.; Martin, A. S. Governance Trends in Protected Areas: Experiences from the Parks in Peril Program in Latin America and the Caribbean. Parks in Peril Innovations in Conservation Series. Arlington, Virginia, USA: The Nature Conservancy. 2007.

Bardin, L. Análise de Conteúdo. São Paulo: Edições 70. $3^{\mathrm{a}}$ reimp. da $1^{\mathrm{a}}$ ed. 2016.

Barett, C. B.; Gibson, C. C.; Hoffman, B.; Mccubbins, M. D.; The Complex Links between Governance and Biodiversity. Conservation Biology, 20(5), 1358-1366, 2006.

Bernstein, S. Legitimacy in Global Environmental Governance, Journal of International Law and International Relations, 1(1-2), 139-66, 2005.

Bevir, M. Governança democrática: uma genealogia. Revista de Sociologia e Política, 19, 39, 103-114, 2011. doi: 10.1590/S0104-44782011000200008

Borrini-Feyerabend, G. Governance of protected areasinnovation in the air... In: IUCN Comission on Environmental, Economical and Social Policy, 12. Community Empowement for Conservation, 92-101. September. 2003.

Borrini-Feyerabend, G. Governance of protected areas, participation and equity. In: Secre-tariat of the Convention on Biological Diversity. Biodiversity issues for consideration in the planning, establishment and management of protected 
area sites and networks. Montreal, SCBD, 164 pages and i to iv. (CBD Technical Series no. 15), 2004.

Borrini-Feyerabend, G.; Dudley, N.; Jaeger, T.; Lassen, B.; Broome, N. P.; Phillips, A.; Sandwith, T. Governança de Áreas Protegidas: da compreensão à ação. Série Diretrizes para melhores Práticas para Áreas Protegidas, No. 20, Gland, Suiça: UICN. xvi + 124pp, 2017.

Brasil. Lei Federal no 9.985 de 18 de julho de 2000. Regulamenta o art. 225, § 1o, incisos I, II, III e VII da Constituição Federal, institui o Sistema Nacional de Unidades de Conservação da Natureza e dá outras providências. D.O.U. em: 19/07/2000.

Brasil. Decreto $n^{\circ}$. 4.340, de 22 de Agosto de 2002, Regulamenta artigos da Lei ${ }^{\circ} 9.985$ de 18 de Julho de 2000, que dispõe sobre o Sistema Nacional de Unidades de Conservação - SNUC. D.O.U. em: 23/08/2002.

Brasil. Decreto de 05 de Junho de 2006. Dispõe sobre a criação da Reserva Extrativista de Canavieiras, localizada nos Municípios de Canavieiras, Belmonte e Una, Estado da Bahia, e dá outras providências. D.O.U. de 06/06/2006.

Câmara, J. B. D. Governança ambiental no Brasil: ecos do passado. Revista de Sociologia e Política, 21(46), 125-146, 2013. doi: 10.1590/S0104-44782013000200008

Cardozo, L. S.; Porto, M. F.; Pimentel, P. C.; Rodrigues, J. S.; Schiavetti, A.; Campiolo, S. Discussões do Conselho Deliberativo da Reserva Extrativista de Canavieiras, Bahia, Brasil: da gestão pesqueira à ambiental. Revista da Gestão Costeira Integrada, 12, 463-475, 2012. Disponível em: http://www.scielo.mec.pt/pdf/rgci/v12n4/v12n4a06.pdf.

Cozzolino, L.F. F. Unidades de Conservação e os processos de Governança Local: o caso da APA do Sana (Macaé, RJ). Dissertação. Psicossociologia de Comunidades e Ecologia Social Programa EICOS. Instituto de Psicologia da Universidade Federal do Rio de Janeiro. Rio de Janeiro: 2005.

Cunha, C. C.; Loureiro, C. F. B. Reservas Extrativistas: limites e contradições de uma territorialidade seringueira. In.: XIX Encontro Nacional de Geografia Agrária, São Paulo, 1-25, 2009. Disponível em: http://revista-theomai. unq.edu.ar/NUMERO20/10ArtCunha.pdf.

Davidson, J.; Lockwood, M.; Curtis, A.; Stratford, E.; Griffi- th, R. Pathways to good practice in regional NRM governan$c e$ : Project summary and achievements. Governance Principles for Regional Natural Resource Management, Report $\mathrm{N}^{\mathrm{o}}$ 1. Austrália, 2006. Disponível em: http://citeseerx.ist.psu. edu/viewdoc/download?doi=10.1.1.624.2435\&rep=rep1\&type $=$ pdf

Dias, M.; Gomes, R.; Batista, S.; Campiolo, S.; Schiavetti, A. Participação popular na criação de unidades de conservação marinha: o caso da Reserva Extrativista de Canavieiras. Revista DireitoGV, 14, 3, 2018. doi: 10.1590/23176172201834

Dudley, N. (Ed.). Guidelines for Applying Protected Area Management Categories. Gland, Switzerland: IUCN. x + 86pp. 2008.

Eklund, J.; Cabeza, M. Quality of governance and effectiveness of protected areas: crucial concepts for conservation planning. Annals of the New York Academy of Sciences, 1399(1), 27-41, 2017. doi: 10.1111/nyas. 13284

Enrione, A.; Mazza, C.; Zerboni, F. Institutionalizing Codes of Governance. American Behavioral Scientist, 49(7), 961-973, 2006.

Filgueiras, F. Indo além do gerencial: a agenda da governança democrática e a mudança silenciada no Brasil. Revista de Admnistração Pública, 52(1), 71-88, 2018. doi: 10.1590/0034-7612161430

Fonseca, I. F.; Bursztyn, M. A Banalização da Sustentabilidade: reflexões sobre governança ambiental em escala local. Sociedade e Estado, 24(1), 17-46, 2009.

Gomides, J. E.; Silva, A. C. O Surgimento da expressão "Governance", Governança e Governança Ambiental. Revista de Ciências Gerenciais, XIII(18), 177-194, 2009.

Graham, J.; Amos, B.; Plumptre, T. Governance Principles for protected areas in the 21st century. Vth IUCN Worls Parks Congress, Durban, South África. Otawwa: Institute of governance. 2003. Disponível em: https://www.files.ethz. ch/isn/122197/pa_governance2.pdf.

Grindle, M. S. Good Enough Governance: Poverty Reduction and Reform in Developing Countries. Governance: An International Journal of Policy, Administrattion, and Institutions, 17(4), 525-548, 2004. 
Grindle, M. S. Good Enough Governance Revisited. Development Policy Review, 25. 553-574, 2007.

Ibama - Instituto Brasileiro do Meio Ambiente e dos Recursos Naturais Renováveis. Instrução Normativa $\mathrm{N}^{\circ} 83$, de 5 de janeiro de 2006. Brasilia. Disponível em: http://www. ibama.gov.br/sophia/cnia/legislacao/IBAMA/IN0083050106.PDF.

IBGE - Instituto Brasileiro de Geografia e Estatística. Cidades: 2010. Portal Brasil em Síntese. Disponível em: https:// cidades.ibge.gov.br/brasil/ba/canavieiras.

ICMBio - Instituto Chico Mendes de Conservação da Biodiversidade. Instrução Normativa $N^{\circ} 02$, de 18 de setembro de 2007. Brasília: DOU em 20/09/2007.

ICMBio - Instituto Chico Mendes de Conservação da Biodiversidade. Termo de Referência para Apoio na Elaboração do Plano de Manejo Participativo da Reserva Extrativista de Canavieiras/BA. 2009a.

ICMBio - Instituto Chico Mendes de Conservação da Biodiversidade. Portaria ICMBio $n^{\circ} 71$ de 03 de Setembro de 2009. 2009b. Brasília: DOU de 04/09/2009.

ICMBio - Instituto Chico Mendes de Conservação da Biodiversidade. Portaria ICMBio $n^{\circ} 79$ de 05 de Agosto de 2016. Brasília: DOU de 09/08/2016.

ICMBio - Instituto Chico Mendes de Conservação da Biodiversidade. Portaria ICMBio $n^{\circ} 313$ de 11 de Abril de 2018. 2018. Brasília: DOU de 13/04/2018.

Ivanova, M.; Gordon, D.; Roy, J. Towards Institutional Symbiosis: Business and the United Nations in Environmental Governance. RECIEL, 16 (2), 2007.

Jacobi, P. R. Governança institucional de problemas ambientais. Politica \& Sociedade, 4(7), 119-137, 2005. doi: $10.5007 / \% 25 \mathrm{x}$

Kardos, M. The reflection of good governance in sustainable development strategies. Procedia - Social and Behavioral Sciences, 58, 1166-1173, 2012. doi: 10.1016/j. sbspro.2012.09.1098

Krahmann, E. National, Regional, and Global Governance: One Phenomenon or Many? Global Governance, 9, 323346, 2003.
Khan, M. S.; Bhagwat, S. A. Protected Areas: A Resource or Constraint for Local People? Mountain Research and Development, 30(1), 14-24, 2010.

Lee, T. A Framework for Protected Area Governance for the Twenty-first Century. Paper for the Fifth World Parks Congress, "Benefits Beyond Boundaries," held in Durban, South Africa, 8-17, 2003.

Leftwich, A. Governance, the State and the Politics of Development, Development and Change, 25, 36, 1994. doi: 10.1111/j.1467-7660.1994.tb00519.x

Lockwood, M. Good governance for terrestrial protected areas: a framework, principles and performance outcomes. Journal of Environmental Management, 91, 754-766, 2010. doi: 10.1016/j.jenvman.2009.10.005

Lockwood, M.; Davidson, J.; Curtis, A.; Stratford, E.; Griffith, R. Governance Principles for Natural Resource Management, Society \& Natural Resources, 23, 2010. doi: 10.1080/08941920802178214

Loureiro, C. F. B.; Cunha, C. C. Educação ambiental e gestão participativa de unidades de conservação: elementos para se pensar a sustentabilidade democrática. Ambiente \& Sociedade, XI(2), 237-253, 2008. Disponível em: http:// www.scielo.br/pdf/asoc/v11n2/v11n2a03.pdf.

Manos, B.; Kenward, R.; Arampatzis, S.; Papathanasiou, J. Research on Governance and Ecosystems Management for the conservation of Biodiversity. Key Messages and Policy Guidelines. In.: 12th International Conference on Environmental Science and Technology. Rhodes, Greece, 8-10, september, 2011.

MMA - Ministério do Meio Ambiente. Cadastro Nacional de Unidades de Conservação. Dados Consolidados. Atualizado em 01.02.2019. Disponível em: http://www. mma.gov.br/areas-protegidas/cadastro-nacional-de-ucs/ dados-consolidados.

Mota, A. C. Y. A. Acoountability no Brasil: os cidadãos e seus meios institucionais de contole dos representantes. Programa de Pós-Graduação em Ciência Política da Faculdade de Filosofia, Letras e Ciências Humanas, Universidade de São Paulo. São Paulo: 250p. 2007. doi: 10.11606/T.8.2007. tde-25052007-141025. 
Newig, J.; Fritsch, O. Environmental Governance: Participatory, Multi-Level - and Effective? Enviromenal Policy and Governance, 19, 197-214, 2009. doi: 10.1002/eet.509

Nobre, D.; Schiavetti, A. Acordos de Pesca, Governança e Conselho Deliberativo de Reserva Extrativista: caso da Resex de Cassurubá, Caravelas, Bahia, Brasil. Boletim do Instituto de Pesca, 39(4), 445-455, 2013. Disponível em: https://www.pesca.sp.gov.br/39_4_445-455.pdf .

Nobre, D.; Trigueirinho, D. A.; Cinti, A.; Schiavetti, A. Governance of the Cassurubá Extractive Reserve, Bahia State, Brazil: an analysis of strengths and weaknesses to inform policy. Marine Policy, 77, 44-55, 2017. doi: 10.1016/j. marpol.2016.12.008

Prado, D. S.; Seixas, C. S. Da floresta ao litoral: instrumentos de cogestão e o legado institucional das Reservas Extrativistas. Desenvolvimento e Meio Ambiente, 48, Edição especial: 30 Anos do Legado de Chico Mendes, 281-298, 2018. doi: 10.5380/dma.v48i0.58759. e-ISSN 2176-9109

Prost. C. Reservas extrativistas marinhas: avanço ou retrocesso? Desenvolvimento e Meio Ambiente, 48, Edição especial: 30 Anos do Legado de Chico Mendes, 321-342, 2018. doi: 10.5380/dma.v48i0.58351. e-ISSN 2176-9109

Rauschmayer, F.; Paavola, J.; Wittmer, H. European Governance of Natural Resources and Participation in a Multi-Level Context: An Editorial. Environmental Policy and Governance, 19, 141-147, 2009.

Rhodes, R. A. W. The New Governance: Governing without government. Political Studies: XLIV, 652-667, 1996. doi: 10.1111/j.1467-9248.1996.tb01747.x

Santiso, C. Good Governance and Aid Effectiveness: The World Bank and Conditionality. The Georgetown Public Policy Review, 7(1), 1-22, 2001. Disponível em: http://www. cheapassignmenthelp.com/wp-content/uploads/2015/06/ swap108.pdf .

Santos, C. Z.; Schiavetti, A. Reservas Extrativistas Marinhas do Brasil: contradições de ordem legal, sustentabilidade e aspectos ecológicos. Boletim do Instituto de Pesca, 39, 479-494, 2013. Disponível em: https://www.pesca.sp.gov. br/39_4_479-494.pdf.

Santos, C. Z.; Schiavetti, A. Assessment of the manage- ment in Brazilian Marine Extractive Reserves. Ocean \& Coastal Management, 93, 26-36, 2014. doi: 10.1016/j. ocecoaman.2014.03.007

Santos, M. H. C. Governabilidade, Governança e Democracia: Criação de Capacidade Governativa e Relações Executivo-Legislativo no Brasil Pós-Constituinte. Dados [online], 40, 3, 1997. doi: 10.1590/S0011-52581997000300003

Sheng, Y. K. Good Urban Governance in Southeast Asia. Environment and Urbanization Asia1, 1(2), 131-147, 2010. doi: $10.1177 \% 2 \mathrm{~F} 097542531000100203$

Simoncini, R.; Borrini-Feyerabend, G.; Lassen, B. Policy Guidelines on Governance and Ecosystem Management for Biodiversity Conservation. GEM-CON-BIO - Governance and Ecosystem Management for the Conservation of Biodiversity. 2008. Disponível em: https://www.iucn. org/sites/dev/files/import/downloads/booklet_final_version_20080423.pdf

Souza, B. B. G. Levantamento participativo de bens e serviços ambientais para estudos de valoração em reservas extrativistas em áreas de manguezais. In.: Ix Encontro Nacional da Ecoeco. Brasília: DF, Out. 2011.

Steffek, J. Discursive legitimation in environmental governance. Forest Policy and Economics, 11, 313-318, 2009. doi: 10.1016/j.forpol.2009.04.003

Van Kersbergen, K.; Van Waarden, F. 'Governance' as a bridge between disciplines: cross-disciplinary inspiration regarding shifts in governance and problems of governability, accountability and legitimacy. European Journal of Political Research, 43, 143-171, 2004.

Vasconcellos, M.; Diegues, A.C.; Kalikoski, D.C. Coastal Fisheries of Brazil. In: Salas, S. et al. (Eds.). Coastal Fisheries of Latin America and the Caribbean. FAO Fisheries and Aquaculture Techinical Paper. Rome, 73-116, 2011. Disponível em: http://www.fao.org/3/a-i1926e.pdf. 